\title{
Eavesdropping on cooperative communication within an ant-butterfly
}

\section{mutualism}

\section{Mark A. Elgar ${ }^{1} \bullet$ David R. Nash ${ }^{2} \bullet$ Naomi E. Pierce ${ }^{3}$}

${ }^{1}$ School of BioSciences, University of Melbourne, Victoria 3010, Australia

${ }^{2}$ Centre for Social Evolution, Department of Biology, University of Copenhagen, DK-2100 Copenhagen, Denmark

${ }^{3}$ Department of Organismic and Evolutionary Biology, Harvard University, Cambridge, MA 02138, USA

Key words: Jalmenus evagoras, Iridomyrmex, Araneidae, exploitation, chemical signals, foraging, mating costs, kairomone

Running head: Elgar et al: Exploitation of an inter-specific mutualism 
Abstract Signalling is necessary for the maintenance of inter-specific mutualisms but is vulnerable to exploitation by eavesdropping. While eavesdropping of intra-specific signals has been studied extensively, such exploitation of inter-specific signals has not been widely documented. The juvenile stages of the Australian lycaenid butterfly, Jalmenus evagoras, form an obligate association with several species of attendant ants, including Iridomyrmex mayri. Ants protect the caterpillars and pupae, and in return are rewarded with nutritious secretions. Female and male adult butterflies use ants as signals for oviposition and mate searching respectively. Our experiments reveal that two natural enemies of J. evagoras, araneid spiders and braconid parasitoid wasps, exploit ant signals as cues for increasing their foraging and oviposition success respectively. Intriguingly, selection through eavesdropping is unlikely to modify the ant signal.

\section{Introduction}

Communication is crucial for many inter-specific mutualisms, yet theoretical models of mutualism (e.g. Doebeli and Knowlton 1998; Foster and Wenseleers 2006) typically stress fitness benefits for each partner, such as nutritional rewards or protection from enemies, and pay less attention to the signalling systems required to generate or sustain these relationships. Such a perspective is critical because individuals must produce and receive signals to identify and alert individuals to the presence of their mutualistic partners, as well as to modify investment in mutualistic activities. Importantly, while selection will favour an efficient signalling system, the signals maintaining the mutualism may also be subject to exploitation by unintended receivers, because signals have a source, and hence can reveal the location of the signaller as well as provide information intended for the receiver (see also Goodale et al. 2010).

Signal exploitation by eavesdroppers, which include predators, parasitoids and parasites, has been reported for most sensory modalities and among diverse taxa (Stevens 2013). The majority of studies document specialized eavesdroppers that locate their victims by detecting intra-specific signals involving courtship or social behaviour, typically exerting a selection pressure on signal design (e.g., Cade 1975; Tuttle and Ryan 1981; Zuk and Kolluru 1998; Peake et al 2001; Kim et al. 2009; Brandley et al 2013, but see Beckers et al 2012). Defence against eavesdropping may include changing the timing of signalling (e.g. Lewkiewicz and Zuk 2004), modifying signal intensity (e.g. Endler 1980), changing the signal modality (e.g. Belwood and Morris 1987), employing private signals (e.g. Nakano et al. 2008), or even mimicry (Igic et al. 2015). Inter-specific signals are not likely to be any less vulnerable to eavesdropping, but have received less attention (e.g. Ranganathan and Borges 2009; Schatz and Hossaert-McKey 2010; Vergara et al. 2011; Hsieh et al. 2012; Baigrie et al 2014).

Associations between ants and lycaenid butterfly larvae provide remarkable examples of symbioses (Pierce et al. 2002). In mutualistic contexts, lycaenid caterpillars provide ants with nutrient-rich secretions (Pierce and Nash 1999; Daniels et al 2005) in exchange for protection against predators and parasites (Pierce and Mead 1981; Pierce et al. 1987; Fiedler et al. 1996). Signalling between ants and lycaenids is required to assemble these relationships: the lycaenid larvae have specialized glands that secrete 
substances capable of attracting and appeasing ants (Kitching 1983; Agrawal and Fordyce 2000; Axén et al. 1996; Hojo et al 2008; but see Oliver and Stein 2011), while adult lycaenids may use the volatile intraspecific chemical signals of their ant partners as cues for oviposition (e.g. Pierce and Elgar 1985; Wagner and Kurina 1997; Fraser et al 2002; but see also Fürst and Nash 2010; Patricelli et al 2015), thereby increasing the likelihood that eggs and young larvae are discovered by the tending ants.

The Imperial hairstreak, Jalmenus evagoras (Donovan) forms an obligate mutualism with its tending ant Iridomyrmex mayri (Forel). The ants acquire nutrients from the larvae and pupae, and in return provide essential protection (Pierce et al. 1987). Larvae and pupae aggregate, attracting myriad attending ants, and numerous adult males are attracted to these aggregations as pupae are about to eclose (Elgar and Pierce 1988). The adult butterflies use volatile pheromones from the ants as cues when searching for mates (Elgar \& Pierce 1988) or oviposition sites (Pierce and Elgar 1985). Several lines of evidence suggest that predators and parasitoids of J. evagoras may similarly use the ants as cues to locate the lycaenid larvae. First, several species of orb-weaving spiders construct webs on food plants infested with the juveniles of J. evagoras and their tending ants, often positioning their webs adjacent to the larval and pupal aggregations: opportunistic surveys (over six days, with 10-68 webs per survey) reveal that $5 \%( \pm 2 \%)$ of the observed spiders had recently captured an adult J. evagoras. Studies of field populations also reveal higher levels of mortality by Apanteles (Braconidae) wasps on larvae that were tended by ants than on those that had attendant ants experimentally excluded (Pierce and Nash 1999).

We investigate whether these spiders and parasitoids eavesdrop on the chemical communication system that maintains the mutualism between J. evagoras and its attending ants. Specifically, we ask: (1) is the distribution of spider webs, both between and within food plants, associated with the distribution of aggregations of J. evagoras; (2) is the persistence of orb-webs on food plants influenced by the presence of ants; and (3) is the searching behaviour of Apanteles parasitoids influenced by the presence of tending and non-tending ants?

\section{Methods}

\section{Spider predators}

We observed J. evagoras at two sites separated by approximately $10 \mathrm{~km}$ : Panton's Gully and Cathedral Rock, both located near the town of Ebor in north-eastern NSW, Australia. The butterflies at these sites feed predominantly on Acacia melanoxylon (R. Br.), and rarely on Acacia decurrens (Willd.) and Acacia mearnsii (De Wild.). All observations made here were with individuals feeding on A. melanoxylon. At least three species of orb-weaving spiders are commonly found on the Acacia foodplants of the butterflies. These spiders include Plebs ebernus (Keyserling), "Cyclosa" fuliginata (Koch), and another unidentified species, probably closely related to "C." fuliginata. Since we were unable to distinguish confidently between the species while in the field, we incorporated all of the spiders into a single category. 
Site surveys - In each site, we located and tagged an individual tree (average height $1.4 \mathrm{~m}$, range $0.7-2.2 \mathrm{~m}$ ) that was host to juvenile stages of J. evagoras, and then located another host plant (typically less than $10 \mathrm{~m}$ away) that was matched for height but was not host to J. evagoras. We located 18 pairs of trees at Cathedral Rock, and 15 pairs of trees at Panton's Gully. We censused each plant, recording the number of larvae and pupae of $J$. evagoras, the total number of orb-weaving spider webs, and the body length of the resident spider. Webs were included in our census only if they contained a resident spider.

Additionally, we noted the number of webs that were located within $50 \mathrm{~cm}$ of each cluster of larvae and pupae of J. evagoras on six large (> $3 \mathrm{~m}$ in height) trees. A "cluster" contained a minimum of 3 pupae and/or larvae of J. evagoras that were within $5 \mathrm{~cm}$ of each other, and we identified 74 clusters (range $7-20$ clusters per tree). We then selected, at the same height on the same tree, a random location by dividing the plane (horizontal) view of the plant into eight sectors, randomly selecting a sector (by choosing a numbered piece of paper from a hat), and then locating that sector on the tree. We recorded the number of spider webs located within $50 \mathrm{~cm}$ of that location.

Field experiment - We selected 36 host plants, which had not been previously censused and were $>3 \mathrm{~m}$ apart that contained juvenile stages of J. evagoras, and recorded the plant height and number of larvae and pupae. We then designated pairs of plants that were matched for both size and number of juveniles. For each pair of host plants, we designated one as the control and the other as the experimental. We wrapped a band of plastic marking tape around the base of each plant, and cut away any vegetation that touched the plant. We then removed all of the ants found on the experimental plant, and prevented ants from regaining access to the plant by smearing BirdOff ${ }^{\mathrm{TM}}$ onto the plastic band at the base of the plant. We collected all of the spiders $(N=108)$ from these plants, and marked each spider with a dot of acrylic paint applied to the cephalothorax. In the late afternoon, we released three spiders onto each of the 36 plants, ensuring that no spider was released back onto the same plant from which it had been collected. We subsequently recorded the presence of painted (resident) and unpainted (immigrant) spiders on each plant three times over the next six days. Missing larvae or pupae were replaced to ensure that all host plants had juvenile stages of J. evagoras.

\section{Wasp parasitoids}

Laboratory experiment - Ten Apanteles parasitoids were obtained from caterpillars of J. evagoras collected from Stanthorpe, Queensland. These wasps produce distinctive silk pupal cocoons under the body of the fourth instar larvae from which they emerge, and it was these cocoons that were collected. After eclosion (which usually happened in the late afternoon or evening), each adult parasitoid was kept in a small plastic container with ad libitum water and 10\% honey solution. Parasitoids were introduced into a circular choice chamber provided with three arms: one contained a worker of Iridomyrmex mayri, the second held two workers of I. rufoniger (Lowne) (I. rufoniger is approximately half the mass of I. mayri) and the third contained no ants (Fig. 1). Air was drawn through each of the arms to the centre of the choice chamber by a hose leading to a low flow-rate pump. 
The chamber was marked into six equal sized sectors, reflecting the content of the arms (Fig. 1). The chamber was illuminated from above by a ring light, which minimised any directional biases due to light intensity. Each wasp was placed, as far as possible, into the centre of the choice chamber and allowed to equilibrate for $5 \mathrm{~min}$. The sector that it occupied, together with its activity (walking, resting or grooming) was then recorded at $20 \mathrm{~s}$ intervals for $30 \mathrm{~min}$. The positions of the ant species involved were changed systematically between each test. Wasps were tested once a day from the day after they eclosed for three days or until they died, whichever was longer. The data for each wasp was then combined across trials to avoid pseudo-replication. Five wasps were tested, two of which died on the day of first testing, and one on the second day of testing. Five additional wasps failed to eclose or died within $12 \mathrm{~h}$ of eclosion, and were not tested. Sexing of the wasps was not possible, and all were kept in isolation after eclosion, so that mating was prevented.

The attractiveness of the two ant species was compared by examining the proportion of the total amount of time the wasp spent walking in each sector relative to the positions of the different ant species. Resting or grooming was deemed to be not associated with host-searching behaviour.

\section{Analysis}

Spiders - We used ANOVA to examine the natural variation in the number (log transformed) and size of spiders per plant, with population, height of tree and either presence/absence or total number of juvenile stages (larvae and pupae) as fixed effects. Non-significant $(P>0.1)$ interaction terms were sequentially removed, and we report the reduced model. A mixed-effects model was used to investigate spatial variation in spider numbers (log transformed), with location (aggregation or random location) as a fixed effect and tree identity as a random effect, with the variance partitioned using restricted maximum likelihood (REML). For the field experiment, we used repeated measures ANOVA to examine the variation in spider numbers, with treatment (control or ants removed) and the initial number of larvae and pupae as fixed effects, and sampling time (1, 3 and 6 days from the start of the experiment) as the repeated measure. Reported values are untransformed means \pm SE.

Parasitoids - We used a Friedman test to examine whether the parasitoid spent different relative amounts of time in each of the sectors, given that the variances were not homogenous.

\section{Results}

\section{Spider predators}

Larger numbers of spiders were found on Acacia plants with juvenile stages of $J$. evagoras (ANOVA: $F_{1,61}$ $=13.38, P=0.0005$; Fig. 2$)$ and on taller plants $\left(F_{1,61}=4.96, \beta=0.43 \pm 0.19, P=0.03\right)$. There were no between-site differences in the number of spiders on Acacia plants $\left(F_{1,61}=0.508, P=0.48\right)$. Among host plants that were infested with J. evagoras, the number of spiders also increased with increasing numbers of larvae and pupae $\left(F_{1,32}=8.53, r^{2}=0.22, \beta=0.02 \pm 0.01, P=0.006\right)$. The average size of the spiders in the webs was not related to the height of the plant (ANOVA: $F_{1,49}=0.077, P=0.78$ ) or the presence of 
juveniles of $J$. evagoras $\left(F_{1,49}=0.001, P=0.98\right)$, although the spiders at Cathedral Rock tended to be larger $(7.4 \pm 0.7 \mathrm{~mm})$ than those at Panton's Gully $\left(5.8 \pm 0.6 ; F_{1,49}=4.07, P=0.08\right)$.

The spiders not only preferred trees with juveniles of J. evagoras and their attendant ants, but also preferred to place their orb-webs near aggregations of the larvae and pupae. The mean number of spiders surrounding aggregations of the larvae and pupae of J. evagoras $(1.5 \pm 0.20, N=74)$ was significantly greater than the number found in a random position at an equivalent height on the same tree $(0.3 \pm 0.05$; ANOVA (REML): $F_{1,143}=39.47, P<0.001$ ). These aggregations of $J$. evagoras comprised, on average, 6.8 \pm 0.7 juveniles $(2.5 \pm 0.4$ larvae and $4.3 \pm 0.4$ pupae). Several of the randomly selected locations on the tree were also adjacent to aggregations of J. evagoras and, when considering only these data, the presence of spiders was strongly associated with proximity to an aggregation: random locations were more likely to have spiders if they were adjacent to an aggregation $(94 \%, N=17)$ than if not $(9 \%, N=57$; test for independence: $\left.\chi^{2}=40.9, P<0.001\right)$.

The ant exclusion experiment revealed that the presence of ants alone influenced where the orbweaving spiders located their webs (Fig. 3). More spiders were found on trees with ants compared with trees without ants (ANOVA: $F_{1,32}=8.248, P=0.007$ ), but the number was not associated with the initial number of larvae and pupae located on the tree $\left(F_{1,32}=0.001, P=0.98\right)$. The number of spiders on the plants varied significantly between sampling times $\left(F_{2,31}=4.778, P=0.016\right)$.

\section{Wasp parasitoids}

The Apanteles parasitoids spent roughly $15 \%$ of the time stationary, $45 \%$ of the time grooming and $40 \%$ of the time walking. There was significant variation across the sectors in the proportion of time walking (Friedman test: $Q=11.07, P=0.046$ ) with the most time spent in the sector containing $I$. mayri, and the least in the sector with I. rufoniger (Fig. 4).

\section{Discussion}

This study provides several lines of evidence that orb-web spiders and braconid parasitoids exploit antderived chemical signals used to maintain a mutualistic association between the ants and the larvae of a lycaenid butterfly. The choice-chamber experiments revealed that Apanteles sp., a braconid parasitoid of $J$. evagoras, was attracted to the ant I. mayri, which tends J. evagoras where it was collected, and apparently repulsed by I. rufoniger, which tends J. daemeli and not J. evagoras in the area from which they were collected. These parasitic wasps emerge exclusively from ant-tended larvae in the field (Pierce et al. 1987; Pierce and Nash 1999). The orb-weaving spiders, which capture adult J. evagoras, increase their foraging success by using the chemical volatiles released by I. mayri to build their webs in areas where there is increased adult flight activity: the ant exclusion experiments demonstrated that spiders were more likely to settle (and remain) on A. melanoxylon plants with ants than on plants without ants, and field observations revealed that the abundance of spider webs on trees was positively correlated with the number of larvae and pupae of J. evagoras and thus with the number of tending ants (see Pierce et al. 1987; Axén and Pierce 1998). 
Finally, these spiders located their webs adjacent to aggregations of J. evagoras and their attendant ants, which are frequently visited by flying adults.

These data reveal an intriguing and novel example of an eavesdropping predator that improves its foraging success by exploiting the communication channels that maintain an inter-specific mutualism. Adult females and males of J. evagoras use olfactory signals from their mutualistic partner ants for oviposition (Pierce and Elgar 1985; Fraser et al. 2002) and mate search (Elgar and Pierce 1988) respectively, apparently using the volatile signals for long- and medium distance orientation. Typically, females spend more time fluttering around plants with ants, eventually alighting on them to oviposit, sometimes near aggregations of pupae and larvae. Males similarly pay more attention to plants with ants, as they search for imminently eclosing adults, typically alighting on or adjacent to solitary or aggregating pupae. These pupal aggregations can attract large numbers of males (Elgar and Pierce 1988). The spiders increase their foraging success by using the volatile chemical odours of the ants to locate their webs in plants with considerable ant activity, corresponding with areas with substantial adult $J$. evagoras flight activity. Thus, the inter-specific signals that are crucial for the reproductive success of the adults are the same as those used by their spider predators. Given the proximity of the spider webs to larval and pupal aggregations, it seems that males are the more likely victims of spider predation, although we have insufficient data to confirm this.

Our data support the hypothesis that braconid wasps Apanteles sp use the tending ant species as a host-finding cue. Thus parasitism of the juvenile stages by highly specialized parasitoid wasps can represent a true cost to the association between larvae of J. evagoras and workers of I. mayri. Nevertheless, adult females of J. evagoras use workers of I. mayri as cues in oviposition (Pierce and Elgar 1985), and all exclusion experiments involving the juvenile stages of J. evagoras indicate that the magnitude of this cost to adults is apparently small compared with the benefits to the juvenile stages of protection by ants from other parasitoids and predators (Pierce et al. 2002). Eavesdropping on host signals by parasitoids is widely reported (e.g. Rutledge 1996; Fatouros et al 2008), but these signals are typically intraspecific, revealing the location of mates and/or aggregations. This novel example of eavesdropping on an interspecific signal between mutualistic partners has been implicated in parasitoid host-finding, and contrasts with other studies on parasitism of ant-associated lycaenids. Two other parasitoids, an egg parasitoid (Family Trichogrammatidae) and a pupal parasitoid (Family Chalcidae) attack J. evagoras whether the ants are present or experimentally excluded, but both cause much greater mortality in their absence (mortality with ants excluded $v$ ants present: $48 \%$ vs $11 \%$ and $10 \%$ vs 2\%, respectively; Pierce and Nash 1999). The same pattern occurs in several parasitoid species that attack facultatively ant-associated lycaenids, including Glaucopsyche lygdamus (Pierce and Mead 1981), Drupadia theda, D. ravindra, Cheritra freja (Seufert and Fiedler 1996), and Hemiargus isola (Weeks 2003). The only other case so far reported where ants are used by a parasitoid of a myrmecophilous lycaenid is Ichneumon eumerus, which attacks caterpillars of the parasitic lycaenid butterfly Maculinea alcon (= rebeli) inside the nests of its host Myrmica ants. This species can distinguish between the odours produced by the host ants and non-host Myrmica ants in the initial stage of 
host-finding, but uses additional cues produced by the caterpillars after entering the Myrmica nests to oviposit (Thomas and Elmes 1993). Intriguingly, newly-emerged parasitoid wasps of several species from the braconid subfamily Microgastrinae (which includes Apanteles) readily find and feed on the dorsal nectary organ of their lycaenid butterfly hosts (Schurian et al. 1993), although this appears to be related to nutrition rather than using the ant-directed signals produced by this gland.

The role of olfactory cues for spider foraging is not widely appreciated. The myrmecophile zodarid spider Habronestes bradleyi uses the alarm pheromone of its Iridomyrmex purpureus ant prey as a foraging cue (Allen et al. 1996), and there is increasing evidence that other myrmecophilous spiders can similarly detect volatile odours from ants (Zodarion rubidum (Zodaridae), Cardenas et al. 2006; Pbintella piantensiscan (Salticidae) and Scytodes sp. (Scytodae), Nelson and Jackson 2014, Habrocestum pulex (Salticidae), Clark et al. 2000). Western black widow spiders (Latrodectus hesperus) are more likely to locate their webs in microhabitats previously inhabited by their prey (Johnson et al. 2011), while lycosid spiders Pardosa milvina and Trochosa ruricola avoid microhabitats previously inhabited by a common predator (Schonewolf et al. 2006; see also Mestre et al. 2014)). The legs of both juvenile and adult male and female orb-weaving spiders are covered in sensilla that function in mechano-chemical cue reception (Foelix 2010). Adult males locate females via the volatile sex pheromones produced by sexually receptive females (Gaskett 2007), and also use silk-bound chemicals to further distinguish between females of different populations (Henneken et al 2016) and mating status (e.g. Gaskett et al 2004). Which pheromones of I. mayri the spiders use are unknown, but these data raise the intriguing possibility that web site selection in orb-weaving spiders can be mediated by olfactory cues, including prey odours (see also Johnson et al. 2011).

Once the spiders have arrived on a tree inhabited by ants and lycaenid butterflies, they may utilize more local cues to locate their webs adjacent to the larval aggregations and/or pupal clusters. Vibratory cues are likely candidates for the spiders at this close range. While chemical signals play a primary role in mediating lycaenid/ant interactions, lycaenids and ants also communicate via substrate borne stridulation (e.g. Devries 1990; Travassos and Pierce 2000; Barbero et al. 2009). The larvae and pupae of Jalmenus evagoras generate vibrational signals that are important in attracting and maintaining an ant guard, suggesting that these substrate-borne vibrations form part of the cooperative communication system. Given the sensitivity of orb-web spiders to vibrations, it seems likely that the spiders can detect these stridulations and respond accordingly. In particular, they may be particularly sensitive to the vibrations of pupae, ensuring that their webs are located near the flight paths of both males and females.

Avoiding being attacked by the myriad numbers of ant workers that tend the larvae and pupae of $J$. evagoras and patrol the surrounding areas is a significant issue for the spiders. One potential line of defence for the spiders is to remain on the web: Zhang et al. (2012) discovered that the surface of the silk of the golden orb-weaver Nephila antipodiana contains a pyrrolidine alkaloid, 2-pyrrolidinone, which acts as a repellent to workers of three species of myrmecine ants (Monomorium pharaonis, Pheidole angulicollis, and an unidentified species of Monomorium). The presence of this chemical on the silk of orb-web spiders is 
taxonomically widespread (e.g. Henneken et al. 2015; Daiqin Li, pers. comm.), and appears to repel the workers of species from other sub-families, including smaller, unidentified species of Iridomyrmex (MA Elgar, pers. obs.). Of course, the spider must initially spend some time on the substrate of the plant while it releases the first strands of silk that form the initial, web-supporting bridge. However, a spider that encounters a worker ant can quickly leap off the vegetation, while still suspended by a silk thread. Thus, the workers are unlikely to be able to mount a strong defence against orb-web spiders that prey on their mutualistic partners.

In theory, eavesdropping can exert a considerable selection pressure on the nature of the signalling system, resulting in modifications of the signal, or even favouring alternative private channels (Stevens 2013). This is especially likely in signalling systems where both signaller and receiver suffer similarly strong negative effects of eavesdropping. For example, eavesdropping on sexual signals may result in fitness losses for both sexes, through mortality for the signaller and/or loss of reproductive success for the receiver (Stevens 2013). Adaptive responses to these costs are less likely in the lycaenid/ant mutualism, because the relationship is asymmetric: the survival of the larvae and pupae of J. evagoras depends critically on the presence of tending ants (Pierce et al. 1987). However, while the ants benefit from the association (Pierce and Nash 1999), their colonies can still thrive in the absence of the butterflies. As a consequence, there is little opportunity for selection to favour changes in both the signal produced by the ant and the capacity for the butterfly to detect and act on that signal. This asymmetric opportunity for selection is not likely in parasitic lycaenids, such as Maculinea, because the evolutionary interests of the ants and parasitoid wasps are aligned.

Acknowledgements We thank Bill Piel for identifying the spiders, and the Australian Research Council (DP120100162) for financial support.

\section{References}

Agrawal A, Fordyce J (2000) Induced indirect defence in a lycaenid-ant association: the regulation of a resource in a mutualism. Proc R Soc B 267: 1857-1861

Allan RA, Elgar MA, Capon RJ (1996) Exploitation of an ant chemical alarm signal by the zodariid spider Habronestes bradleyi Walckenaer. Proc R Soc B 263: 69-73

Axén AH, Pierce NE (1998) Aggregation as a cost-reducing strategy for lycaenid larvae. Behav Ecol 9: 109-115

Axén A, Leimar O, Hoffman V (1996) Signaling in a mutualistic interaction. Anim Behav 52: 321-333

Baigrie BD, Thompson AM, Flower TP (2014) Interspecific signaling between mutualists: food-thieving drongos use a cooperative sentinel call to manipulate foraging partners. Proc R Soc B 281: 20141232.

Barbero F, Thomas JA, Bonelli S, Balletto E, Schonrogge K (2009) Queen ants make distinctive sounds that are mimicked by a butterfly social parasite. Science 323: 782-785

Beckers OM, Wagner WE Jr (2012) Eavesdropping parasitoids do not cause the evolution of less conspicuous signalling behaviour in a field cricket. Anim Behav 84: 1475-1462 
Belwood JJ, Morris GK (1987) Bat predation and its influence on calling behavior in neotropical katydids. Science 238: 64-67

Brandley NC, Speiser DI, Johnsen S (2013) Eavesdropping on visual secrets. Evol Ecol 27: 1045-1068

Cade W (1975) Acoustically orienting parasitoids: fly phonotaxis to cricket song. Science 190: 1312-1313

Cardenas M, Jiros P, Pekar S (2012) Selective olfactory attention of a specialised predator to intraspecific chemical signals of its prey. Naturwissenschaften 99: 597-605

Clark RJ, Jackson RR, Cutler B (2000) Chemical cues from ants influence predatory behavior in Habrocestum pulex, an ant-eating jumping spider (Araneae, Salticidae). J Arachnol 28: 309-318

Daniels H, Gottsberger G, Fiedler K (2005) Nutrient composition of larval nectar secretions from three species of myrmecophilous butterflies. J Chem Ecol 31: 2805-2821

Devries PJ (1990) Enhancement of symbioses between butterfly caterpillars and ants by vibrational communication. Science 248: 1104-1106

Doebeli M, Knowlton N (1998) The evolution of interspecific mutualisms. Proc Nat Acad Sci USA 95: 8676-8680

Elgar MA, Pierce NE (1988) Male lifetime mating success and female fecundity of an ant-tended lycaenid butterfly. In: Clutton-Brock TH (ed) Reproductive Success: Studies of Individual Variation in Contrasting Breeding Systems. University of Chicago Press, Chicago, pp 59-75

Endler JA (1980) Natural selection on color patterns in Poecilia reticulata. Evolution 34: 76-91

Fatouros NE, Huigens ME, van Loon JJA, Dicke M, Hilker M (2008) Butterfly anti-aphrodisiac lures parasitic wasps. Nature 433: 704

Fiedler K, Hölldobler H, Seufert P (1996) Butterflies and ants: the communicative domain. Experientia 52: 14-24

Foelix R (2010) Biology of Spiders, $3^{\text {rd }}$ ed. Oxford University Press, Oxford

Foster KR, Wenseleers TJ (2006) A general model for the evolution of mutualisms. J Evol Biol 19: 1283-1293

Fraser AM, Tregenza T, Wedell N, Elgar MA, Pierce NE (2002) Oviposition tests of ant preference in a myrmecophilous butterfly. J Evol Biol 15: 861-870

Fürst MA, Nash DR (2010) Host ant independent oviposition in the parasitic butterfly Maculinea alcon. Biol Lett 6: $174-176$

Gaskett AC (2007) Spider sex pheromones: emission, reception, structures, and functions. Biol Rev 82: 26-48

Gaskett AC, Herberstein ME, Downes BJ, Elgar MA (2004) Life-time male mating preferences in a sexually cannibalistic orb-web spider (Araneae: Araneidae). Behaviour 141: 1197-1210

Goodale E, Beauchamp G, Magrath RD, Nieh JC, Ruxton GD (2010) Interspecific information transfer influences animal community structure. Trends in Ecology and Evolution 25: 354-361.

Henneken J, Jones TM, Goodger J, Walter A, Elgar MA (2016) Diet influences female signals used in male mate choice. Anim Behav 108: 215-221.

Hojo MK, Wada-Katsumata A, Ozaki M, Yamaguchi S, Yamaoka R (2008) Gustatory synergism in ants mediates a species-specific symbiosis with lycaenid butterflies. J Comp Physiol A 194: 1043-1052

Hsieh H-Y, Liere H, Soto EJ, Perfecto I (2012) Cascading trait-mediated interactions induced by ant pheromones. Ecol Evol 2: 2181-2191 
Igic B, McLachlan J, Lehtinen I, Magrath RD. 2015 Crying wolf to a predator: deceptive vocal mimicry by a bird protecting young. Proc R Soc B 282: 20150798

Johnson A, Revis O, Johnson JC (2011) Chemical prey cues influence the urban microhabitat preferences of Western black widow spiders, Latrodectus hesperus. J Arachnol 39: 449-453

Kim JW, Brown GE, Dolinsek IJ, Brodeur NN, Leduc AOHC, Grant JWA (2009) Combined effects of chemical and visual information in eliciting antipredator behaviour in juvenile Atlantic salmon Salmo salar. J Fish Biol 74: 1280-1290

Kitching RL (1983) Myrmecophilous organs of the larvae and pupa of the lycaenid butterfly Jalmenus evagoras (Donovan). J Nat Hist 17: 471-481

Lewkiewicz DA, Zuk M (2004) Latency to resume calling after disturbance in the field cricket, Teleogryllus oceanicus, corresponds to population-level differences in parasitism risk. Behav Ecol Sociobiol 55: 569-573

Mestre L, Bucher R, Entling MH (2014) Trait-mediated effects between predators: ant chemical cues induce spider dispersal. J Zool 293: 119-125

Nakano, R, Skals N, Takanashi T, Surlykke A, Koike T, Yoshida K, Maruyama H, Tatsuki S, Ishikawa Y (2008) Moths produce extremely quiet ultrasonic courtship songs by rubbing specialized scales. Proc Nat Acad Sci USA 105: 11812-11817

Nelson XJ, Jackson RR (2014) Timid spider uses odor and visual cues to actively select protected nesting sites near ants. Behav Ecol Sociobiol 68: 773-780

Oliver JC, Stein LR (2011) Evolution of influence: signaling in a lycaenid-ant interaction. Evol Ecol 25: 1205-1216

Patricelli D, Barbero F, Occhipinti A, Bertea CM, Bonelli S, Casacci LP, Zebelo SA, Crocoll C, Gershenzon J, Maffei ME, Thomas JA, Balletto E (2015) Plant defences against ants provide a pathway to social parasitism in butterflies. Proc R Soc B 282: 20151111

Peake TM, Terry AMR, McGregor PK, Dabelsteen T (2001) Male great tits eavesdrop on simulated male-tomale vocal interactions. Proc R Soc B 268: 1183-1187

Pierce NE (1987) The evolution and biogeography of associations between lycaenid butterflies and ants. In: Harvey PH, Partridge L (eds) Oxford Surveys in Evolutionary Biology. Oxford University Press, Oxford, pp 89-116

Pierce NE (1989) Butterfly-ant mutualisms. In: Grubb PJ, Whittaker JB (eds) Toward a More Exact Ecology. Blackwell Scientific, Oxford, pp 299-324

Pierce NE, Elgar MA (1985) The influence of ants on host plant selection by Jalmenus evagoras, a myrmecophilous lycaenid butterfly. Behav Ecol Sociobiol 16: 209-222

Pierce NE, Nash DR (1999) The Imperial Blue: Jalmenus evagoras (Lycaenidae). In: Kitching RL, Sheermeyer E, Jones RE, Pierce NE (eds) The Biology of Australian Butterflies. CSIRO Press, Melbourne, pp 279-315

Pierce NE, Mead PS (1981) Parasitoids as selective agents in the symbiosis between lycaenid butterfly larvae and ants. Science 211: 1185-1187

Pierce NE, Kitching RL, Buckley RC, Taylor MFJ, Benbow KF (1987) The costs and benefits of cooperation between the Australian lycaenid butterfly, Jalmenus evagoras, and its attendant ants. Behav Ecol Sociobiol 21: $237-248$ 
Pierce NE, Braby MF, Heath A, Lohman DJ, Mathew J, Rand DB, Travassos MA (2002) The ecology and evolution of ant association in the Lycaenidae (Lepidoptera). Ann Rev Entomol 47: 733-771

Ranganathan Y, Borges RM (2009) Predatory and trophobiont-tending ants respond differently to fig and fig wasp volatiles. Anim Behav 77: 1539-1545

Rutledge, CE (1996) A survey of identified kairomones and synomones used by insect parasitoids to locate and accept their hosts. Chemoecology 7: 121-131

Schatz, B, Hossaert-McKey M (2010) Ants use odour cues to exploit fig-fig wasp interactions. Acta Oecologica 36: 107-113

Schonewolf KW, Bell R, Rypstra AL, Persons MH (2006) Field evidence of an airborne enemy-avoidance kairomone in wolf spiders. J Chem Ecol 32: 1565-1576

Schurian KG, Fiedler K, Maschwitz U (1993) Parasitoids exploit secretions of myrmecophilous Lycaenid butterfly caterpillars (Lycaenidae). J Lep Soc 47: 150-154.

Seufert P, Fiedler K (1996) Life-history diversity and local coexistence of three closely related lycaenid butterflies (Lepidoptera, Lycaenidae) in Malaysian rainforests. Zool Anzeiger 234: 229-239.

Siemers BM, Kriner E, Kaipf I, Simon M, Greif, S (2012) Bats eavesdrop on the sound of copulating flies. Current Biol 22: R563-R564

Stevens M (2013) Sensory Ecology, Behaviour, and Evolution. Oxford University Press, Oxford

Thomas JA, Elmes GW (1993) Specialized searching and the hostile use of allomones by a parasitoid whose host, the butterfly Maculinea rebeli, inhabits ant nests. Anim Behav 45: 593-602.

Travassos MA, Pierce NE (2000) Acoustics, context and function of vibrational signalling in a lycaenid butterfly-ant mutualism. Anim Behav 60: 13-26

Tuttle MD, Ryan MJ (1981) Bat predation and the evolution of frog vocalizations in the neotropics. Science 214: $677-678$

Vergara RC, Torres-Araneda A, Villagra DA, Raguso RA, Arroyo MTK, Villagra CA (2011) Are eavesdroppers multimodal? Sensory exploitation of floral signals by a non-native cockroach Blatta orientalis. Current Zool 57: 162-174

Wagner D, Kurina L (1997) The influence of ants and water availability on oviposition behaviour and survivorship of a facultatively ant-tended herbivore. Ecol Entomol 22: 352-360

Weeks JA (2003) Parasitism and ant protection alter the survival of the lycaenid Hemiargus isola. Ecol Entomol 28 : 228-232.

Zhang S, Koh TH, Seah, WK, Lai, YH, Elgar MA, Li, D (2012) A novel property of spider silk: chemical defence against ants. Proc Roy Soc B 279: 1824-1830

Zuk M, and Kolluru GR (1998) Exploitation of sexual signals by predators and parasitoids. Q Rev Biol 73: 415-438 


\section{Figure Legends:}

Fig. 1. Experimental arrangement to test for ant-dependent oviposition by the Apanteles parasitoid. The different sectors of the arena are labelled according to the olfactory cues provided: $\mathrm{M}=$ Iridomyrmex mayri (host ant), $\mathrm{R}=$ Iridomyrmex rufoniger (non-host ant) and $\mathrm{E}=$ Empty. Intermediate sectors are labelled accordingly: (e.g. R-E = Between I. rufoniger and the empty arm). The arena, worker ants and the parasitoid wasp are shown approximately to scale.

Fig. 2. The number of orb-weaving spiders on Acacia when the juvenile stages of J. evagoras were or were not present on the plants. The number of spiders was significantly higher on plants with juveniles of $J$. evageras, but there was no significant between site differences, or site by presence interaction term (see text for details).

Fig. 3. The number of spiders on Acacia melanoxylon plants in the presence and absence of ants. The number of spiders was significantly higher on plants with juveniles of $J$. evagoras, and also varied across the three sampling times, but there was no significant time by treatment interaction.

Fig. 4. The proportion of time spent by the Apanteles parasitoid in the different sectors. See Fig. 1 for an explanation of the labelling of sectors. The parasitoid spent more time in the sector with the butterfly tending ant I. mayri than the non-tending ant I. rufoniger. 
Fig 1.

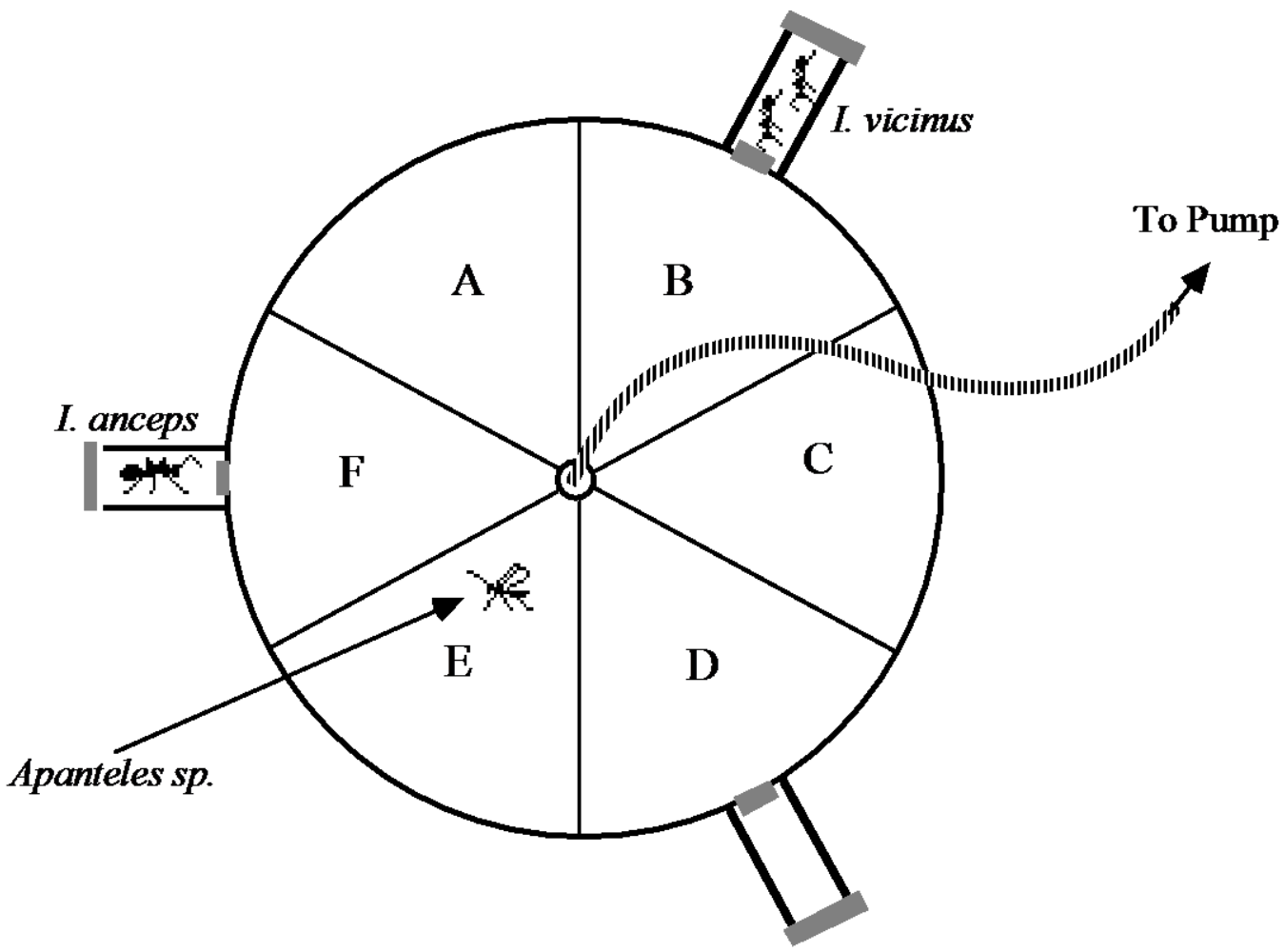




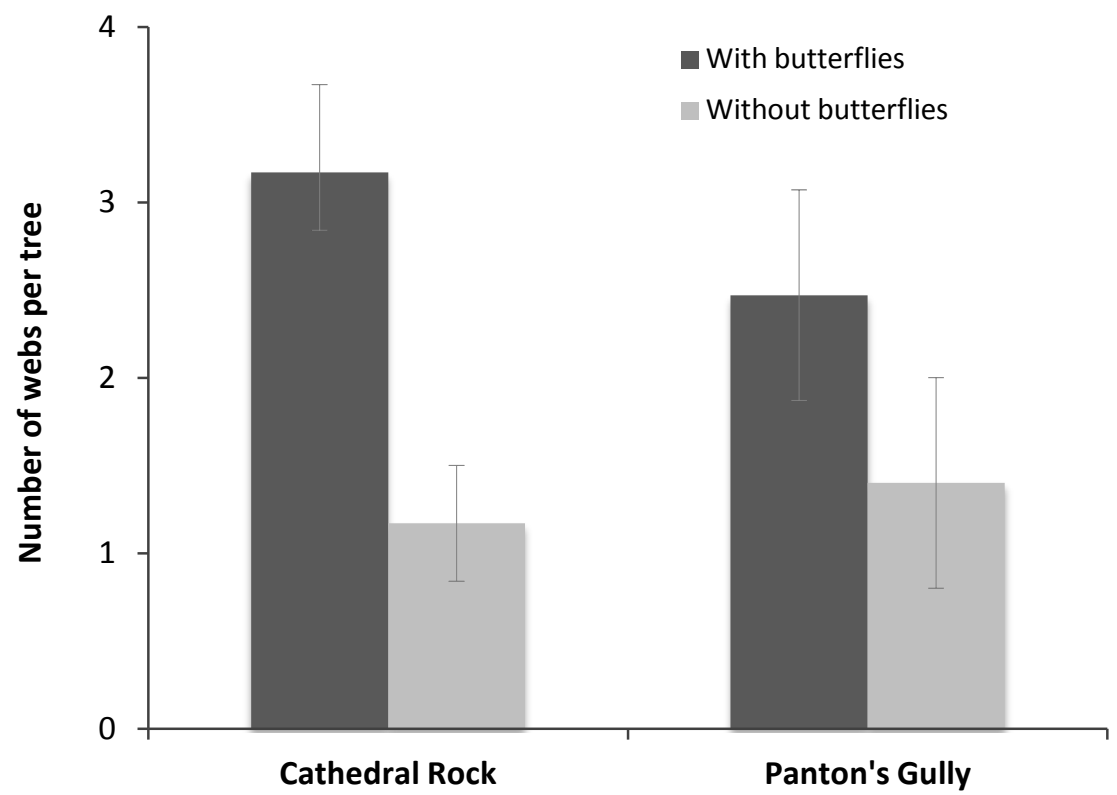




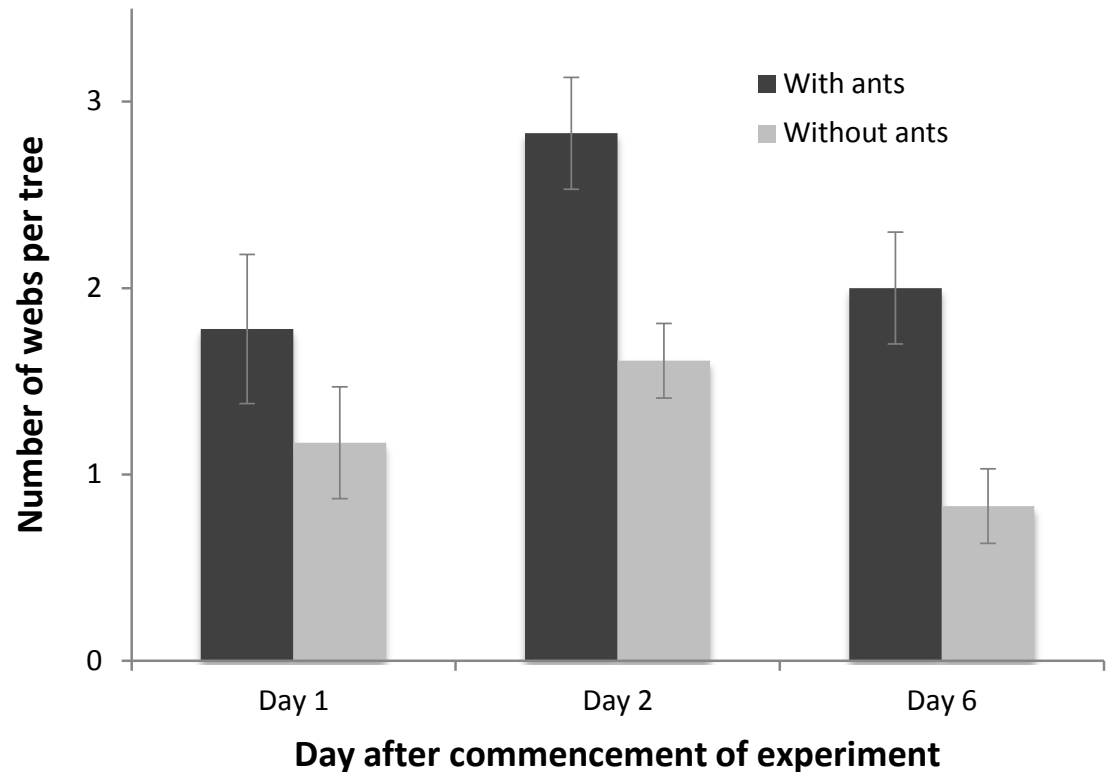


Fig. 4

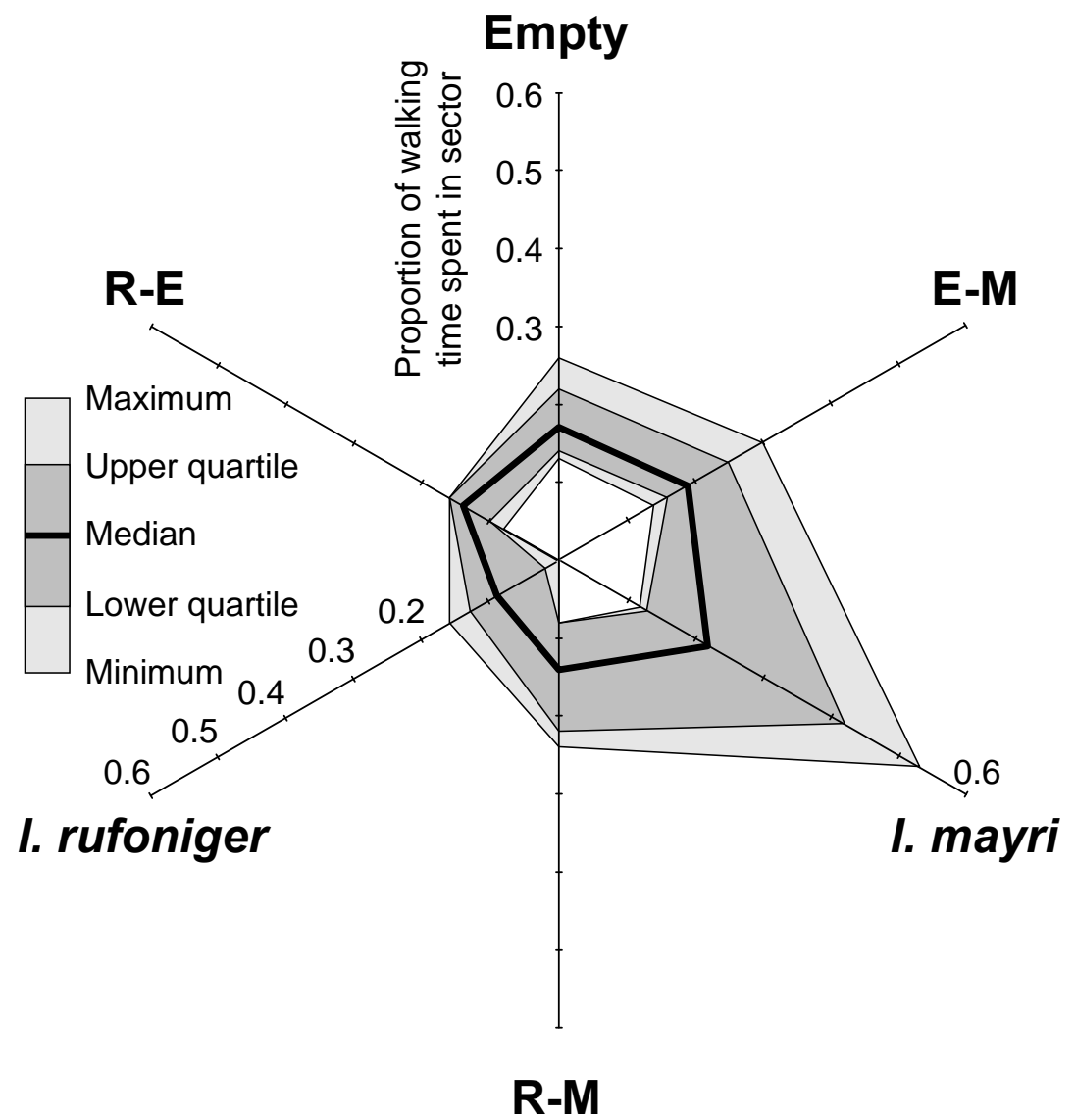




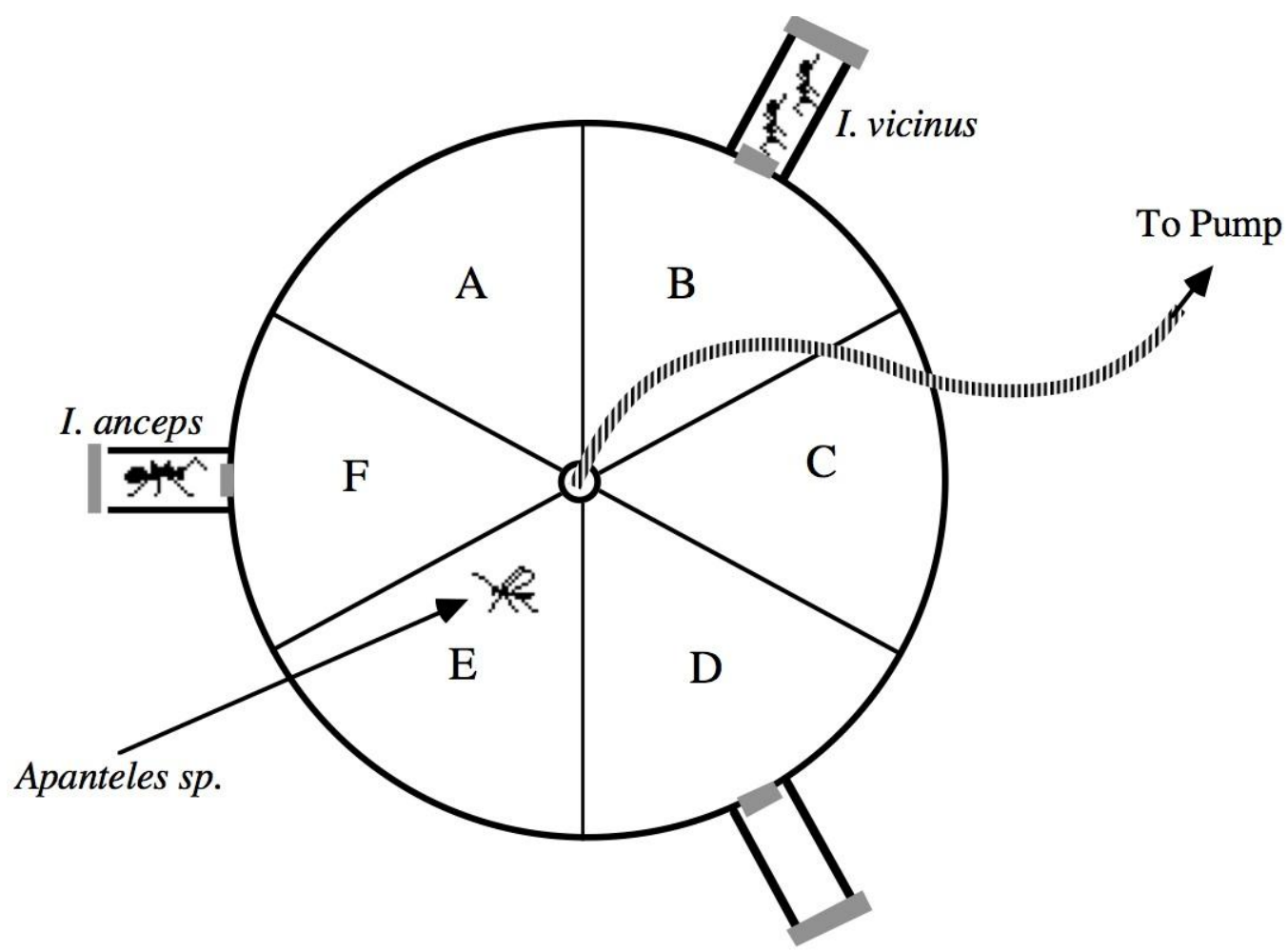




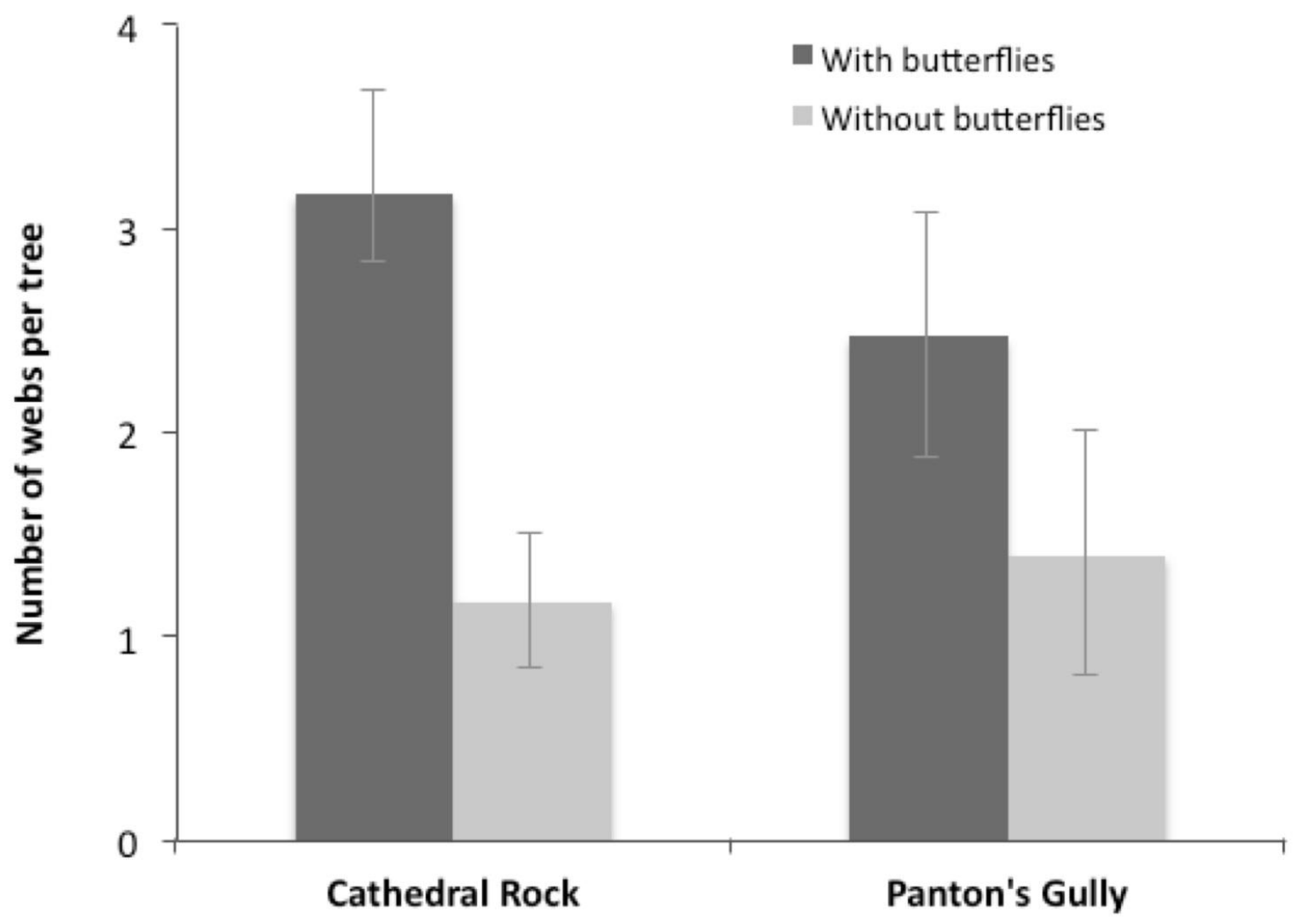




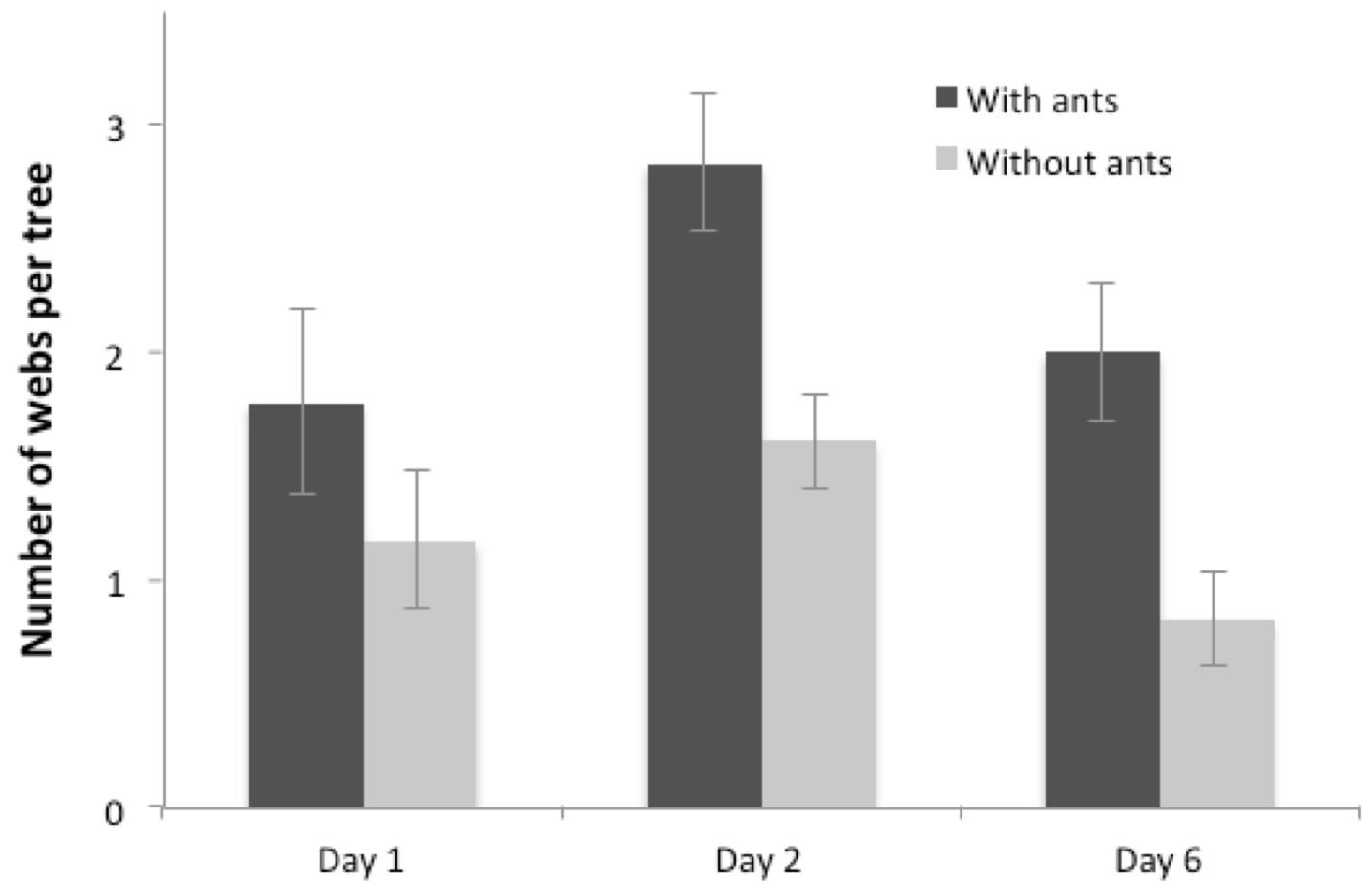

Day after commencement of experiment 


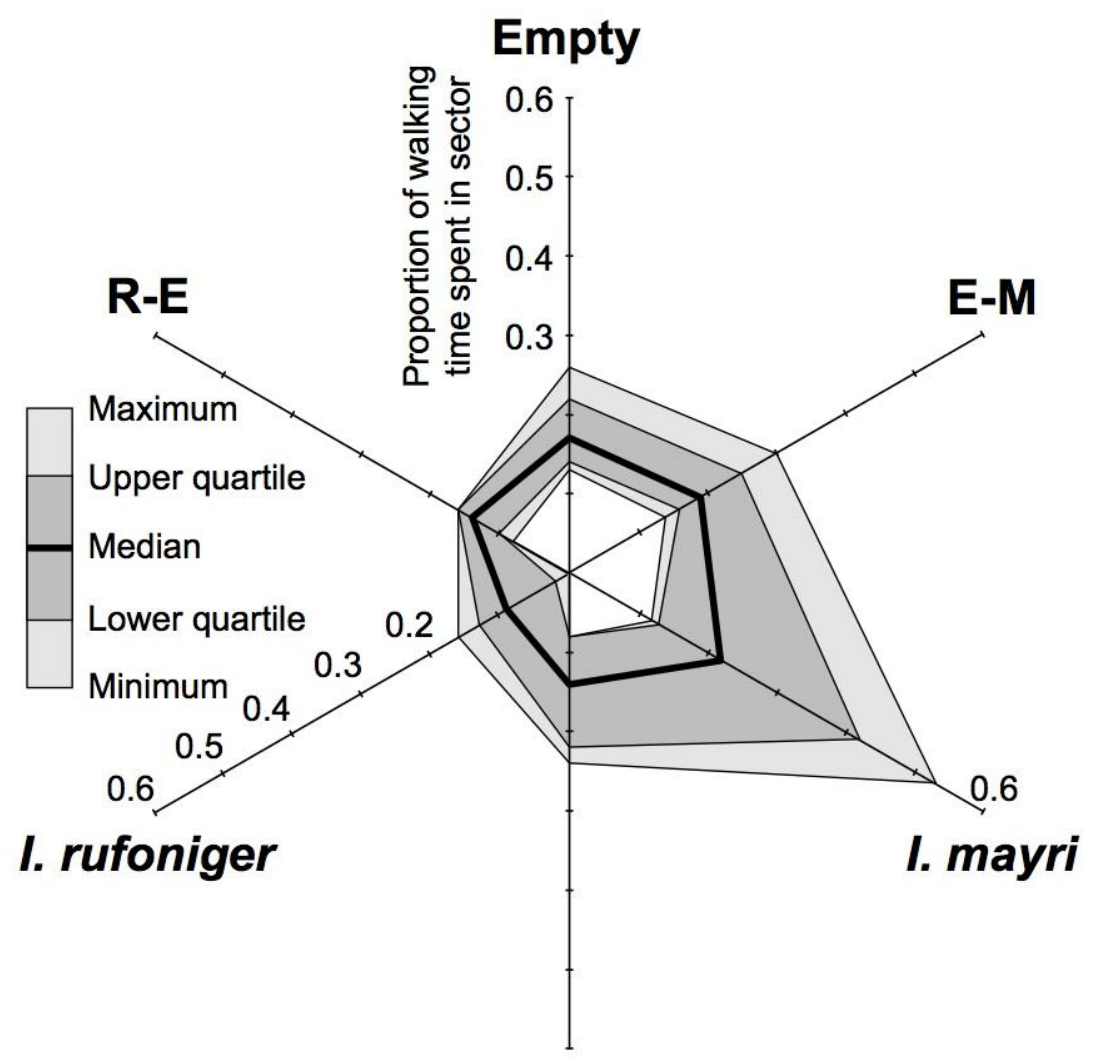

R-M 


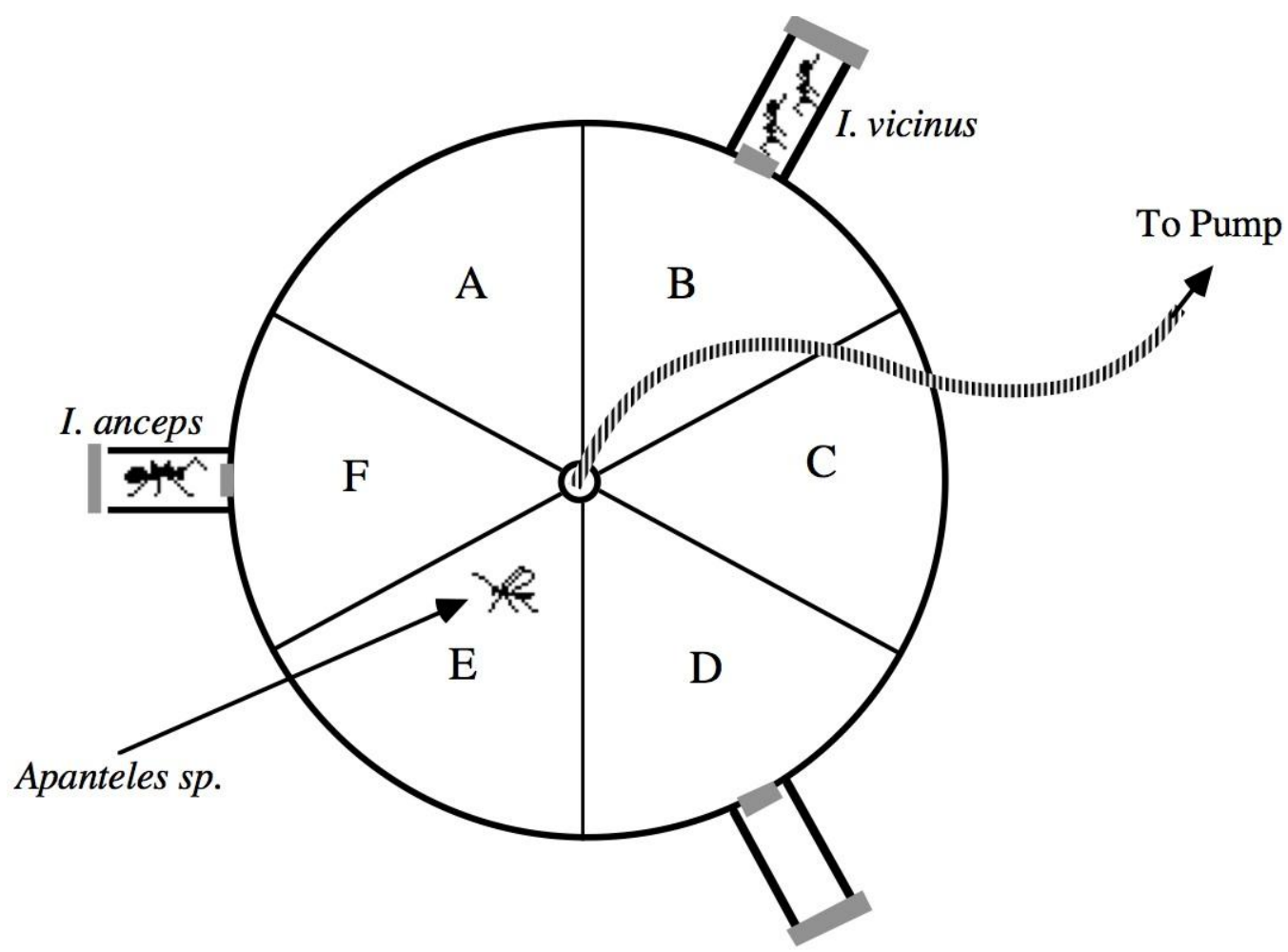




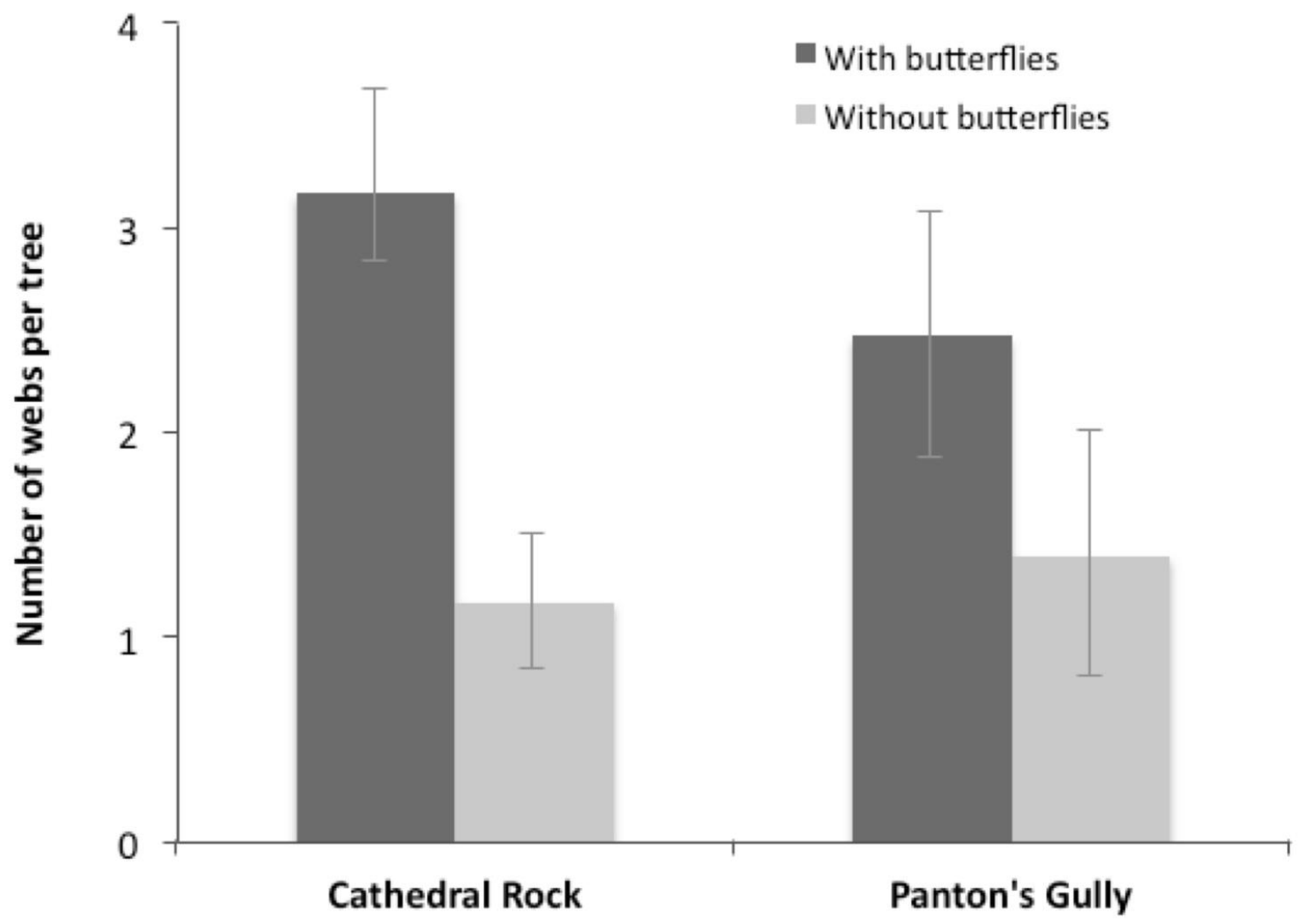




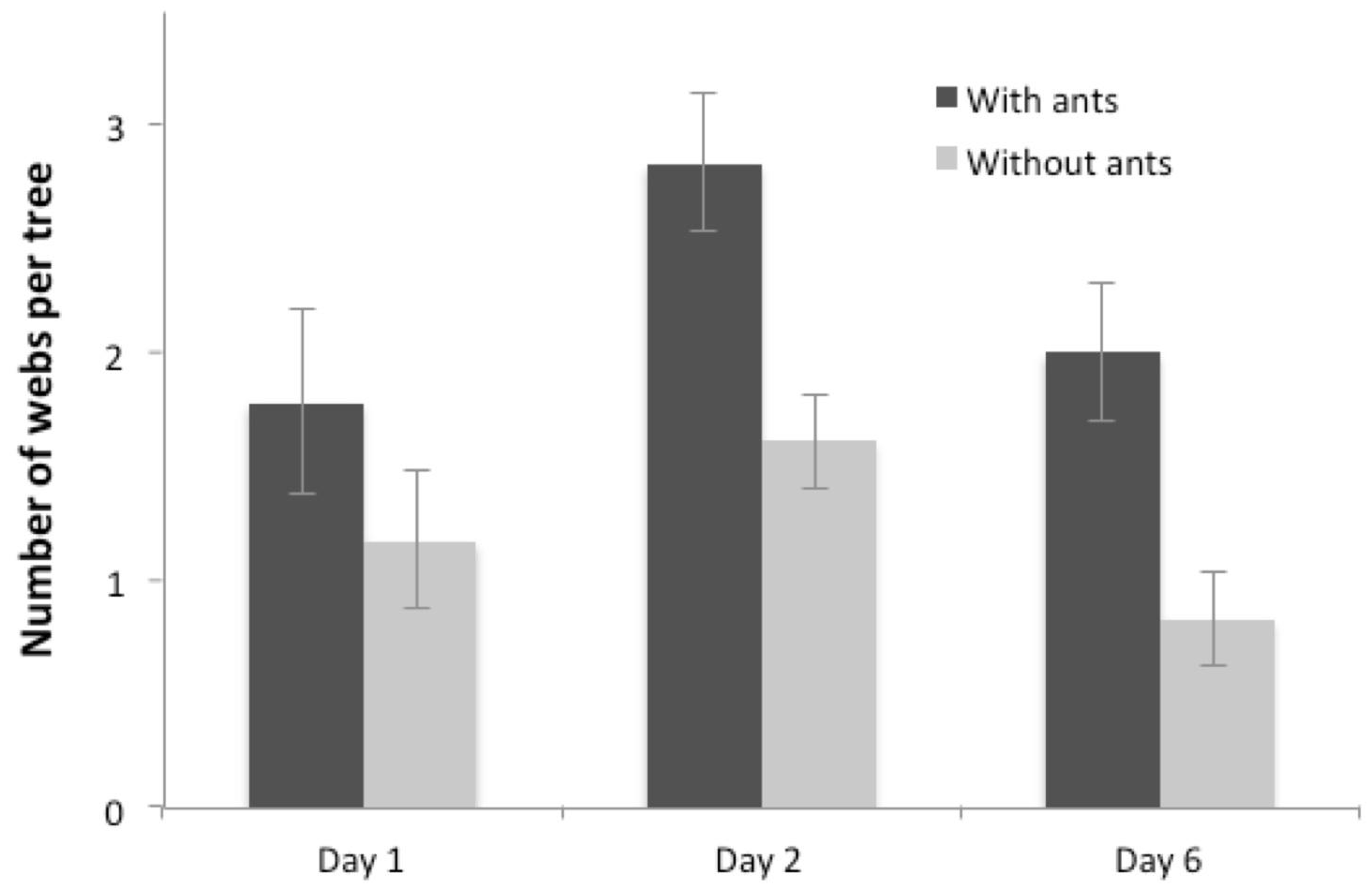

Day after commencement of experiment 


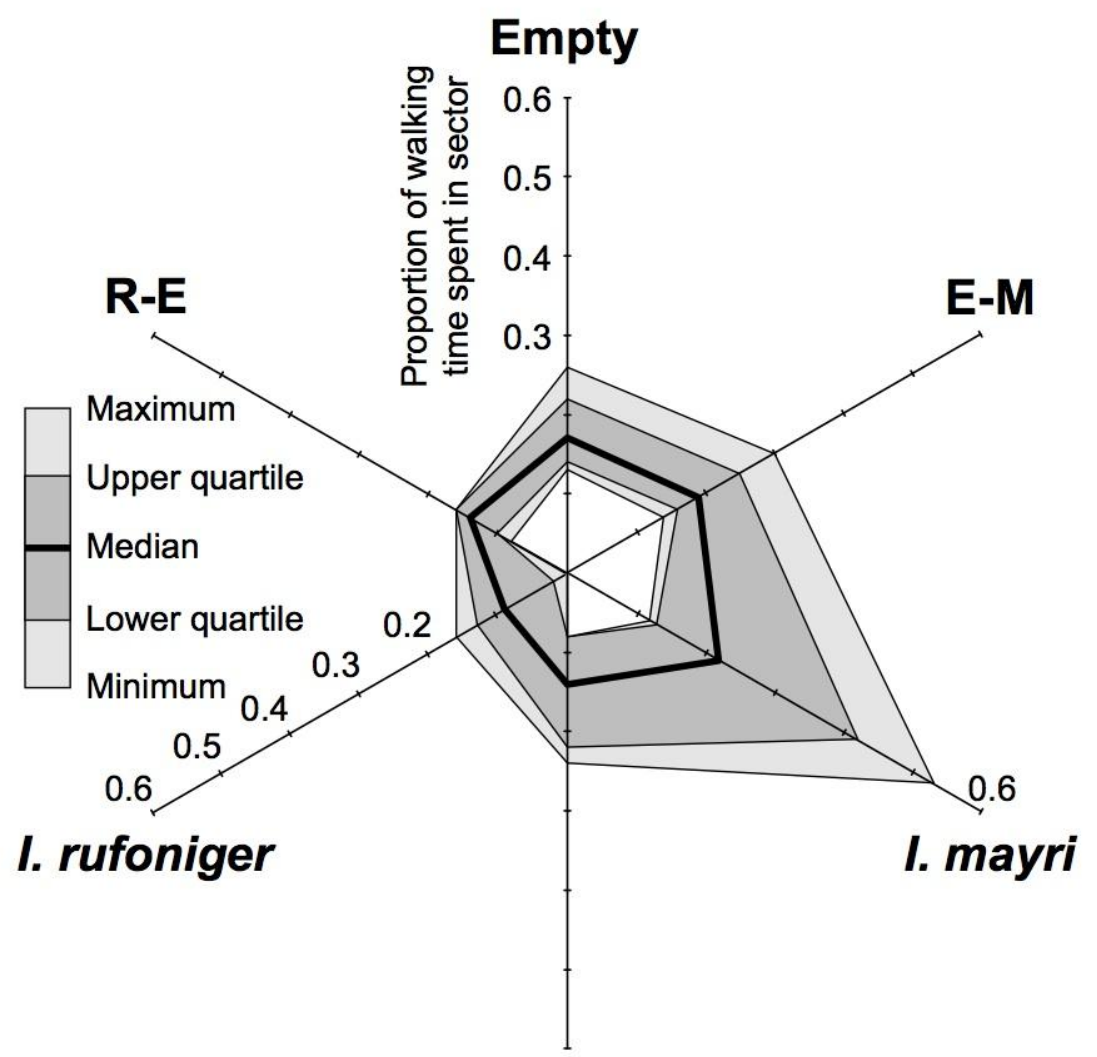

R-M 


\section{University Library}

\section{- M M N E R VA A gateway to Melbourne's research publications}

Minerva Access is the Institutional Repository of The University of Melbourne

Author/s:

Elgar, MA;Nash, DR;Pierce, NE

Title:

Eavesdropping on cooperative communication within an ant-butterfly mutualism

Date:

2016-10-01

Citation:

Elgar, M. A., Nash, D. R. \& Pierce, N. E. (2016). Eavesdropping on cooperative communication within an ant-butterfly mutualism. SCIENCE OF NATURE, 103 (9-10), https:// doi.org/10.1007/s00114-016-1409-5.

Persistent Link:

http://hdl.handle.net/11343/283126 